\title{
PENERAPAN ALGORITMA K-MEANS UNTUK PENGELOMPOKAN SISWA LOLOS SNMPTN DI SMAN 8 BANDUNG
}

\author{
Rahmawati ${ }^{1}$, Toni Arifin $^{2}$ \\ 1 Universitas Adhirajasa Reswara Sanjaya \\ email: amarachma97@gmail.com \\ ${ }^{2}$ Universitas Adhirajasa Reswara Sanjaya \\ email: toni.tfn19@gmail.com
}

\begin{abstract}
Abstrak
Pendidikan merupakan hal yang sangat penting, dengan adanya perguruan tinggi maka semakin meningkatkan kualitas pendidikan di Indonesia. Seleksi Nasional Masuk Perguruan Tinggi Negeri (SNMPTN) merupakan sebuah seleksi nasional yang didasarkan pada nilai rapor dan prestasi. Hal ini juga yang menyebabkan SNMPTN banyak diminati. Siswa yang mengikuti SNMPTN harus menentukan jurusan dan universitas yang tepat agar diterima karena daya tampung SNMPTN terbatas. Pada penelitian ini menggunakan algoritma K-Means dengan tujuan untuk memperoleh informasi mengenai perguruan tinggi mana yang paling banyak diminati oleh siswa siswinya. K- Means merupakan salah satu algoritma yang paling populer karena mudah dan sederhana ketika diimplementasikan. K-Means digunakan untuk mengelompokan data yang memiliki kemiripan. Data yang digunakan berjumlah 86 data. Berdasarkan validasi menggunakan metrik Davies Bouldin Index maka diperoleh 2 cluster yang dinilai dapat mengelompokan data dengan baik. Performance Vector hasil evalusi cluster yang dibentuk sebanyak 2 cluster dengan hasil 0,558 . Cluster 1 dengan jumlah 46 items dan cluster 2 dengan jumlah 40 items.
\end{abstract}

Kata Kunci : K-Means, Cluster, SNMPTN

\begin{abstract}
Education is very important, with the existence of tertiary institutions, the quality of education in Indonesia is increasingly enhanced. National University Entrance Entrance Selection (SNMPTN) is a national selection based on report card grades and achievements. This also causes SNMPTN to be in great demand. Students who take SNMPTN must determine the right direction and university to be accepted because SNMPTN capacity is limited. In this study using the K-Means algorithm with the aim to obtain information about which universities are most in demand by their students. K-Means is one of the most popular algorithms because it is easy and simple when implemented. K-Means are used to group similar data. The data used amounted to 86 data. Based on validation using the Davies Bouldin Index metric, 2 clusters are obtained which are considered to be able to group data well. Performance Vector results of cluster evaluation formed by 2 clusters with 0.558 results. Cluster 1 with 46 items and Cluster 2 with 40 items.
\end{abstract}

Keywords: K-Means, Clusters, SNMPTN 


\section{Pendahuluan}

Dengan seiring berjalannya zaman, pendidikan merupakan hal yang akan terus berkembang dan sangat penting, di Indonesia sendiri cukup sulit untuk mengimbangi perkembangannya (Ndruru \& Limbong, 2018). Fungsi pendidikan yaitu untuk mengembangkan potensi yang dimiliki. Perguruan tinggi merupakan jenjang pendidikan setelah pendidikan menengah atas atau SMA/SMK sederajat. Dengan adanya perguruan tinggi maka semangkin meningkatlah kualitas pendidikan di Indonesia (Amri et al., 2019).

Seleksi Nasional Masuk Perguruan Tinggi Negeri (SNMPTN) adalah sebuah seleksi nasional yang didasarkan pada prestasi akademik seperti nilai rapor dan prestasi lain (Putri et al., 2015). Hal ini menyebabkan SNMPTN menjadi jalur yang banyak diminati, siswa harus menentukan pilihan jurusan dan universitas dengan tepat agar dapat diterima melalui jalur SNMPTN karena daya tampungnya yang terbatas (Prabowo \& Sunyoto, 2015).

Sistem seleksi dan rekrutmen mahasiswa baru telah mengalami berbagai perubahan dan penyempurnaan dari waktu ke waktu. Akurasi dan keadilan (equity) menjadi acuan dominan dalam seleksi mahasiswa baru. Perubahan ini bertujuan untuk meningkatkan kualitas dan keefektifan sistem pendidikan di Indonesia (Lestari, Anis \& Khaeruddin, 2018). Seperti pada data siswa lolos SNMPTN di SMAN 8 Bandung, siswa yang masuk pada seleksi SNMPTN hanya siswa terbaik yang terpilih.

Data mining adalah ilmu yang mempelajari tentang pengumpulan, pembersihan, pengolahan, analisis, dan memperoleh informasi yang berguna dari sebuah data (Saifudin, 2018). Dari sumber lain data mining disebut juga sebagai salah satu cara untuk mengubah data menjadi informasi yang berguna serta dapat menghasilkan ilmu baru sebagai wawasan (Ndruru \& Limbong, 2018). Salah satu metode yang bisa digunakan yaitu clustering, dengan salah satu algoritma yang bisa digunakan adalah K-Means. K-Means adalah salah satu metode pengelompokan data nonhirarki yang mempartisi data. Metode ini mempartisi data dengan karakteristik yang sama ke dalam satu kelompok yang sama dan data yang berkarakteristik berbeda dikelompokkan kedalam kelompok data yang lain (Sadewo et al., 2017).

Pada penelitian sebelumnya yang dilakukan oleh (Ndruru \& Limbong, 2018) dengan memanfaatkan teknik data mining khususnya metode clustering untuk mengelompokan data siswa berdasarkan nilai, dapat menghasilkan informasi mengenai siswa yang berminat untuk memilih jurusan yang diinginkan.

Berdasarkan permasalahan yang ada, maka pada kesempatan kali ini akan dilakukan pengelompokan terhadap data siswa lolos SNMPTN di SMAN 8 Bandung. Data tersebut akan dikelompokan dengan metode clustering menggunakan algoritma K-Means dengan hasil yang diharapkan berupa informasi bagi pihak sekolah untuk mengetahui perguruan tinggi negeri mana paling banyak diambil oleh siswa/i nya.

\section{Metode Penelitian}

Bagian ini menjelaskan tahapan demi tahapan yang penulis lakukan, dalam menyusun laporan ini agar lebih sistematis dan terarah sesuai dengan yang telah direncanakan.

\subsection{Tahapan Penelitian}

1. Pengumpulan data

Pada tahap ini akan dijelaskan data yang didapat berasal darimana dan mampu mendeskripsikan data mana saja yang akan digunakan pada penelitian ini.

2. Pengolahan data awal

Pada tahap ini akan dijelaskan mengenai data yang telah layak dilakukan proses pengolahan. Pengolahan data juga berfungsi untuk mempermudah pembentukan model.

3. Model yang diusulkan

Setelah melakukan pengolahan data awal, pada tahap ini akan dijelaskan mengenai model yang diusulkan yang akan digunakan terhadap data yang sudah ada.

4. Eksperimen dan pengujian model

Pada tahap ini akan menjelaskan tentang eksperimen yang dilakukan hingga terbentuknya model, serta akan menjelaskan bagaimana cara menguji model yang terbentuk tersebut.

5. Evaluasi dan validasi hasil

Pada tahap terakhir ini akan dilakukan evaluasi terhadap eksperimen dan pengujian model yang dilakukan sehingga akan mengetahui validasi hasil dari model yang diusulkan. 


\subsection{Metode Pengumpulan Data}

Data yang digunakan merupakan data siswa lolos SNMPTN di SMAN 8 Bandung yang penulis dapatkan dari web sekolah SMAN 8 Bandung yaitu sman8bdg.sch.id. Data dalam penelitian ini sebanyak 86 data yang terdiri dari atribut nama lengkap, kelas, rata-rata, PTN (Perguruan Tinggi Negeri) dan program studi/jurusan.

\subsection{Pengolahan Data}

Pada tahap ini merupakan tahap untuk memastikan data telah layak dan dapat dilakukan proses pengolahan. Data awal yang penulis peroleh berjumlah 91 data siswa lolos SNMPTN di SMAN 8 Bandung dengan jumlah atribut sebanyak 5 atribut.

Tabel 1. Atribut Keseluruhan

\begin{tabular}{|c|l|l|}
\hline No & \multicolumn{1}{|c|}{ Atribut } & \multicolumn{1}{c|}{ Keterangan } \\
\hline 1 & Nama Lengkap & $\begin{array}{l}\text { Siswa SMAN 8 Bandung } \\
\text { yang lolos mengikuti } \\
\text { SNMPTN }\end{array}$ \\
\hline 2 & Kelas & $\begin{array}{l}\text { Kelas siswa SMAN 8 } \\
\text { Bandung yang lolos } \\
\text { mengikuti SNMPTN }\end{array}$ \\
\hline 3 & Rata-rata & $\begin{array}{l}\text { Nilai siswa SMAN 8 } \\
\text { Bandung yang lolos } \\
\text { mengikuti SNMPTN }\end{array}$ \\
\hline 4 & PTN & $\begin{array}{l}\text { Perguruan Tinggi Negeri } \\
\text { yang dipilih }\end{array}$ \\
\hline 5 & $\begin{array}{l}\text { Program } \\
\text { Studi/Jurusan }\end{array}$ & Program studi yang dipilih \\
\hline
\end{tabular}

Dalam pengolahan data ini dilakukan data cleaning atau pembersihan data yang akan digunakan dalam proses perhitungan, data yang tidak lengkap maka akan dihilangkan. Selain itu dilakukan juga data transformation, data yang jenisnya nominal seperti kelas, PTN (Perguruan Tinggi Negeri) dan program studi/jurusan harus dilakukan proses inisialisasi data terlebih dahulu kedalam bentuk angka atau numerical. Dalam melakukan inisialisasi dapat dilakukan dengan cara pengurutan angka berdasarkan frekuensinya.

Tabel 2. Tabel Inisialisasi Kelas

\begin{tabular}{|c|c|c|c|}
\hline \multicolumn{4}{|c|}{ TABEL KELAS } \\
\hline No & Kelas & Frekuensi & Inisialisasi \\
\hline 1 & XII IPS 1 & 15 & 1 \\
\hline 2 & XII IPS 2 & 10 & 2 \\
\hline 3 & XII IPS 3 & 9 & 3 \\
\hline$\ldots$ & $\ldots$ & $\ldots$ & $\ldots$ \\
\hline
\end{tabular}

\begin{tabular}{|l|l|l|l|}
10 & XII MIPA 7 & 6 & 10 \\
\hline 11 & XII MIPA 8 & 8 & 11 \\
\hline 12 & XII MIPA 9 & 6 & 12 \\
\hline
\end{tabular}

Berikut merupakan tabel inisialisasi dari PTN, yaitu perguruan tinggi negeri yang dipilih oleh siswa SMAN 8 Bandung.

Tabel 3. Tabel Inisialisasi PTN

\begin{tabular}{|c|c|c|c|}
\hline \multicolumn{4}{|c|}{ TABEL UNIVERSITAS } \\
\hline No & Universitas & Frekuensi & Inisialisasi \\
\hline 1 & UPI & 11 & 1 \\
\hline 2 & UNPAD & 47 & 2 \\
\hline$\ldots$ & $\ldots$ & $\ldots$ & $\ldots$ \\
\hline 6 & ISI & 1 & 6 \\
\hline 7 & ITB & 23 & 7 \\
\hline
\end{tabular}

Program studi/jurusan merupakan program studi yang dipilih oleh siswa SMAN 8 Bandung. Berikut merupakan tabel inisialisasi atribut program studi/jurusan.

Tabel 4.

Tabel Inisialisasi Program Studi/Jurusan

TABEL PROGRAM STUDI/JURUSAN

\begin{tabular}{|c|l|c|c|}
\hline No & $\begin{array}{l}\text { Program } \\
\text { Studi/Jurusan }\end{array}$ & Frekuensi & Inisialisasi \\
\hline 1 & $\begin{array}{l}\text { Pendidikan } \\
\text { Khusus }\end{array}$ & 1 & 1 \\
\hline 2 & Akuntansi & 2 & 2 \\
\hline 3 & Ekonomi Islam & 1 & 3 \\
\hline$\ldots$ & \multicolumn{1}{|c}{$\ldots$} & $\ldots$ & $\ldots$ \\
\hline 56 & IImu Aktuaria & 1 & 56 \\
\hline 57 & FTSL & 2 & 57 \\
\hline 58 & Biologi & 1 & 58 \\
\hline
\end{tabular}

\section{Hasil dan Pembahasan}

Pada bagian ini akan dijelaskan pembahasan mengenai hasil penelitian yang penulis lakukan.

\subsection{Perhitungan Algoritma K-Means}

Pada proses perhitungan algoritma K-Means dilakukan dengan beberapa tahapan : 


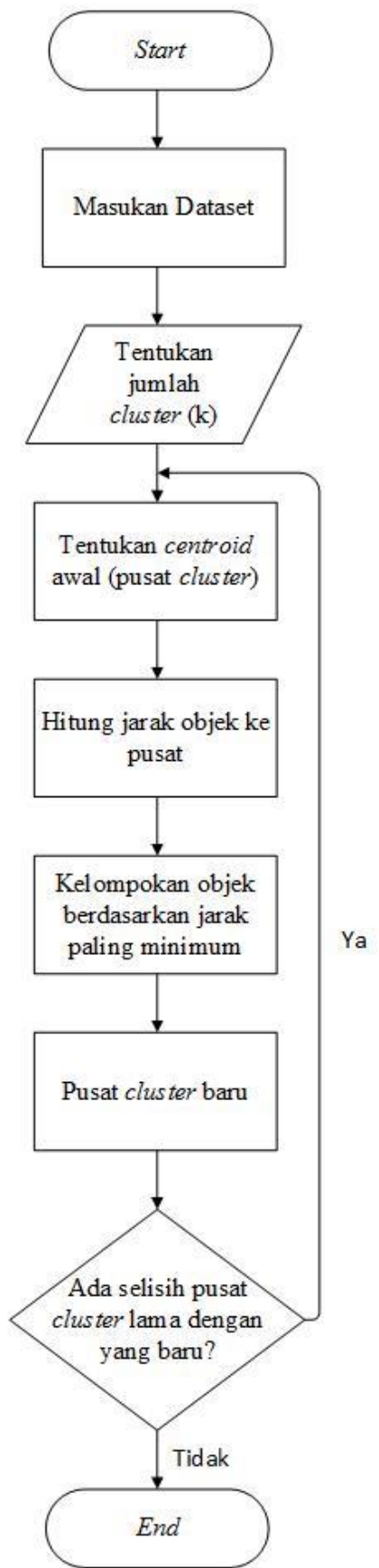

Gambar 1. Flowchart K-Means

Tahapan pertama dalam perhitungan algoritma K-means adalah menentukan jumlah $\mathrm{k}$ (cluster), pada penelitian ini dibentuk 2 cluster yaitu kelompok cluster tertinggi dan rendah. Kemudian menentukan centroid awal, centroid awal dipilih secara random sesuai dengan atribut Nama Lengkap, Kelas, Ratarata, PTN dan Program Studi/Jurusan.

Berikut merupakan dataset siswa lolos SNMPTN di SMAN 8 Bandung yang telah melewati tahap preprocessing diantaranya tahap cleaning atau pembersihan data yang kemudian data yang bertipe nominal dilakukan tahap inisialisasi. Tahap terakhir yaitu transformasi semua data yang telah diinisialisasi.

Tabel 5. Dataset yang sudah di Trasformasi

\begin{tabular}{|c|c|c|c|c|c|}
\hline $\begin{array}{l}\mathrm{N} \\
\mathrm{O}\end{array}$ & $\begin{array}{c}\text { Nama } \\
\text { Lengkap }\end{array}$ & $\begin{array}{c}\text { Kela } \\
\mathrm{s}\end{array}$ & $\begin{array}{l}\text { Rata- } \\
\text { rata }\end{array}$ & $\begin{array}{l}\mathrm{PT} \\
\mathrm{N}\end{array}$ & $\begin{array}{c}\text { Program } \\
\text { Studi/Juru } \\
\text { san }\end{array}$ \\
\hline 1 & $\begin{array}{l}\text { Hesti Ratu } \\
\text { Fadilah }\end{array}$ & 1 & 85.63 & 1 & 1 \\
\hline 2 & $\begin{array}{l}\text { Depinkan } \\
\text { Zalfaa } \\
\text { Faliha } \\
\end{array}$ & 1 & 88.03 & 2 & 2 \\
\hline 3 & $\begin{array}{l}\text { Manda } \\
\text { Amelia } \\
\text { Saraswati }\end{array}$ & 1 & 86.9 & 2 & 3 \\
\hline 4 & $\begin{array}{l}\text { Adri } \\
\text { Mochamad } \\
\text { Ihsan }\end{array}$ & 1 & 86.62 & 1 & 4 \\
\hline 5 & $\begin{array}{l}\text { Azizah } \\
\text { Muthia } \\
\text { Andriana }\end{array}$ & 1 & 87.25 & 2 & 5 \\
\hline 6 & $\begin{array}{l}\text { Ferdiansya } \\
\mathrm{h}\end{array}$ & 1 & 87 & 2 & 6 \\
\hline 7 & $\begin{array}{l}\text { llham } \\
\text { ardian } \\
\text { dahlarizand } \\
y\end{array}$ & 1 & 86.1 & 2 & 7 \\
\hline 8 & $\begin{array}{l}\text { Deswita } \\
\text { Dwi Lestari }\end{array}$ & 1 & 86.07 & 1 & 8 \\
\hline 9 & $\begin{array}{l}\text { Haidar } \\
\text { Husein }\end{array}$ & 1 & 85.9 & 1 & 9 \\
\hline 10 & $\begin{array}{l}\text { Fatimah } \\
\text { Az-zahra }\end{array}$ & 1 & 86.43 & 1 & 10 \\
\hline$\ldots$ & & $\ldots$ & $\ldots$ & $\ldots$ & $\ldots$ \\
\hline 77 & $\begin{array}{l}\text { Alfadli } \\
\text { Maulana } \\
\text { Siddik }\end{array}$ & 11 & 86.8 & 2 & 54 \\
\hline 78 & $\begin{array}{l}\text { Raden } \\
\text { Sylva } \\
\text { Adliani }\end{array}$ & 11 & 88.2 & 2 & 55 \\
\hline 79 & $\begin{array}{l}\text { Wafi } \\
\text { Fahruzzam } \\
\text { an }\end{array}$ & 11 & 86.8 & 2 & 54 \\
\hline 80 & $\begin{array}{l}\text { Sarah } \\
\text { Gustiarini } \\
\text { Rifdah }\end{array}$ & 11 & 89.5 & 7 & 30 \\
\hline 81 & $\begin{array}{l}\text { Farah } \\
\text { Azhariani }\end{array}$ & 12 & 88.9 & 7 & 31 \\
\hline 82 & $\begin{array}{l}\text { M Adhitya } \\
\text { Wicaksana }\end{array}$ & 12 & 86.5 & 2 & 56 \\
\hline 83 & $\begin{array}{l}\text { Meisya } \\
\text { Paramita } \\
\text { Nurhaliza }\end{array}$ & 12 & 88.69 & 7 & 57 \\
\hline 84 & $\begin{array}{l}\text { Canaya } \\
\text { Vania } \\
\text { Rehansha }\end{array}$ & 12 & $\begin{array}{c}86.53 \\
4\end{array}$ & 2 & 58 \\
\hline 85 & $\begin{array}{l}\text { Nadira Aby } \\
\text { Xavier }\end{array}$ & 12 & 88.33 & 7 & 25 \\
\hline 86 & $\begin{array}{l}\text { Farah } \\
\text { Hapsari } \\
\text { Yulistyani }\end{array}$ & 12 & 89.07 & 7 & 57 \\
\hline
\end{tabular}

Tahap selanjutnya yaitu menentukan titik pusat awal dari cluster 
(centroid) yang dipilih secara random. Pada penelitian ini diambil dari data ke 62 dan 23.

Tabel 6. Centroid Awal

\begin{tabular}{|c|c|c|c|c|c|c|}
\hline $\begin{array}{c}\text { Centr } \\
\text { oid }\end{array}$ & $\begin{array}{c}\mathbf{N} \\
\mathbf{0}\end{array}$ & $\begin{array}{c}\text { Nama } \\
\text { Lengk } \\
\text { ap }\end{array}$ & $\begin{array}{c}\text { Kel } \\
\text { as }\end{array}$ & $\begin{array}{c}\text { Rat } \\
\text { a- } \\
\text { rat } \\
\mathbf{a}\end{array}$ & $\begin{array}{c}\text { PT } \\
\mathbf{N}\end{array}$ & $\begin{array}{c}\text { Program } \\
\text { Studi/Jur } \\
\text { usan }\end{array}$ \\
\hline $\begin{array}{c}\text { Cluste } \\
\text { r 0 }\end{array}$ & 6 & $\begin{array}{c}\text { Ayumi } \\
\text { Yulian } \\
\text { i Fuji }\end{array}$ & 8 & $\begin{array}{c}88 . \\
16\end{array}$ & 2 & 45 \\
\hline $\begin{array}{c}\text { Cluste } \\
\text { r1 }\end{array}$ & 2 & $\begin{array}{c}\text { Tesya } \\
\text { Salwa } \\
\text { Iwand } \\
\text { ha }\end{array}$ & 2 & $\begin{array}{c}87 . \\
33\end{array}$ & 2 & 18 \\
\hline
\end{tabular}

Setelah menentikan centroid awal, maka tahap selanjutnya yaitu menghitung jarak setiap data yang ada ke centroid terdekat untuk menentukan cluster menggunakan rumus Euclidean distance.

Berikut contoh perhitungan jarak ke setiap centroid.

$>$ Data ke-1 cluster ke-0

$d(x i c 0)=\sqrt{a^{2}+b^{2}}$

$=\sqrt{(1-8)^{2}+(85,63-88,16)^{2}+(1-2)^{2}+(1-45)^{2}}$

$=\sqrt{49+6,4009+1+1936}=\sqrt{1992,4009}=44,64$

Dari perhitungan data ke-1 dengan cluster ke-0 maka dihasilkan jarak 44,64

$>\quad$ Data ke-1 cluster ke-1

$d(x i c 0)=\sqrt{a^{2}+b^{2}}=$

$\sqrt{(1-2)^{2}+(85,63-87,33)^{2}+(1-2)^{2}+(1-18)^{2}}$

$=\sqrt{1+2,89+1+289}=\sqrt{293,89}=17,14$

Dari perhitungan data ke-1 dengan cluster ke-1 maka dihasilkan jarak 17,14 Hasil perhitungan tersebut yaitu jarak data ke-1 dengan cluster ke-0 sebesar 44,64 jarak dan data ke-1 dengan cluster ke-1 sebesar 17,14. Berikut Tabel IV.3 yang merupakan perhitungan lengkap dari iterasi ke-1.
Tabel 7. Hasil Perhitungan dengan Menggunakan Rumus Euclidean pada Iterasi ke-1

\begin{tabular}{|c|c|c|c|c|}
\hline \multirow{2}{*}{$\begin{array}{l}\text { Data } \\
\text { ke-i }\end{array}$} & \multicolumn{2}{|c|}{$\begin{array}{l}\text { Jarak ke } \\
\text { Centroid }\end{array}$} & \multirow{2}{*}{$\begin{array}{c}\text { Jarak } \\
\text { Terdekat }\end{array}$} & \multirow{2}{*}{$\begin{array}{c}\text { Cluster } \\
\text { yang } \\
\text { diikuti }\end{array}$} \\
\hline & CO & C1 & & \\
\hline 1 & 44.64 & 17.14 & 17.14 & C1 \\
\hline 2 & 43.57 & 16.05 & 16.05 & $\mathrm{C} 1$ \\
\hline 3 & 42.60 & 15.04 & 15.04 & C1 \\
\hline 4 & 41.63 & 14.09 & 14.09 & C1 \\
\hline 5 & 40.62 & 13.04 & 13.04 & C1 \\
\hline 6 & 39.64 & 12.05 & 12.05 & C1 \\
\hline 7 & 38.69 & 11.11 & 11.11 & C1 \\
\hline 8 & 37.73 & 10.18 & 10.18 & C1 \\
\hline 9 & 36.76 & 9.22 & 9.22 & $\mathrm{C} 1$ \\
\hline 10 & 35.75 & 8.17 & 8.17 & C1 \\
\hline 77 & 9.58 & 37.11 & 9.58 & $\mathrm{CO}$ \\
\hline 78 & 10.44 & 38.09 & 10.44 & $\mathrm{CO}$ \\
\hline 79 & 9.58 & 37.11 & 9.58 & $\mathrm{CO}$ \\
\hline 80 & 16.15 & 15.96 & 15.96 & C1 \\
\hline 81 & 15.41 & 17.22 & 15.41 & $\mathrm{CO}$ \\
\hline 82 & 11.82 & 39.30 & 11.82 & $\mathrm{CO}$ \\
\hline 83 & 13.61 & 40.59 & 13.61 & $\mathrm{CO}$ \\
\hline 84 & 13.70 & 41.24 & 13.70 & $\mathrm{CO}$ \\
\hline 85 & 21.00 & 13.23 & 13.23 & C1 \\
\hline 86 & 13.63 & 40.61 & 13.63 & Co \\
\hline
\end{tabular}

Selanjutnya kelompokan data sesuai dengan jarak cluster terdekat. Dari data yang sudah dikelompokan akan didapat centroid baru dari hasil rata-rata setiap cluster. Lakukan langkah tersebut sampai nilai centroid tidak mengalami perubahan.

\subsection{Validasi Hasil}

Berdasarkan validasi menggunakan metrik Davies Bouldin Index pada aplikasi Rapidminer maka diperoleh dua cluster yang dinilai dapat mengelompokan data dengan baik. Performance Vector hasil evaluasi cluster yang dibentuk sebanyak dua cluster dengan nilai 0,558 yang dapat dilihat pada gambar. 


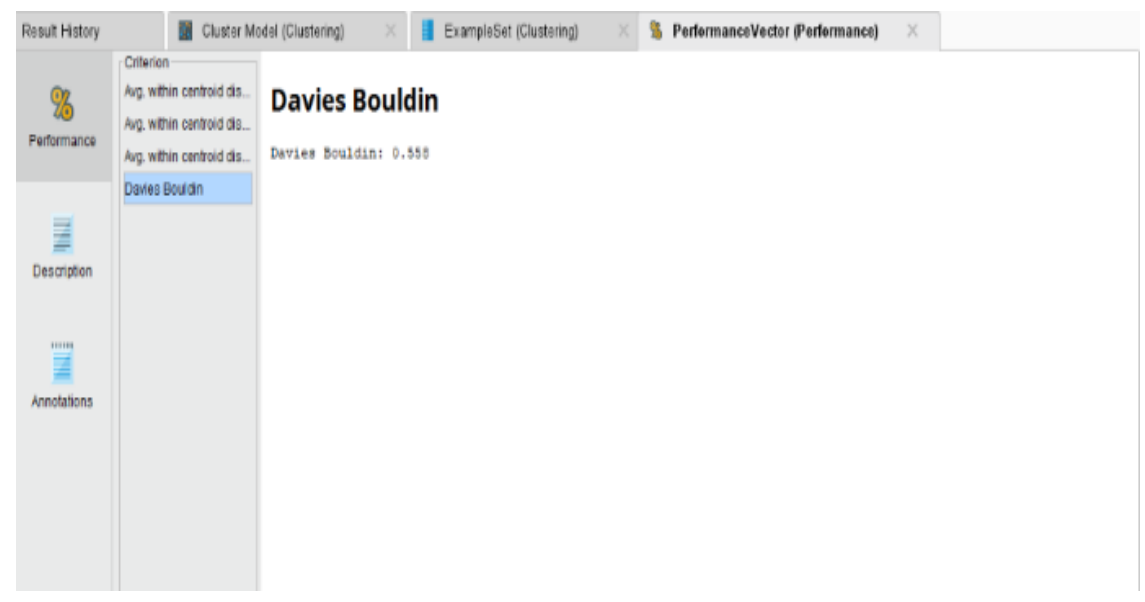

\section{Gambar 2. Performance Vector}

Sebelumnya telah dilakukan pengujian dari $\mathrm{k}=2$ sampai dengan $\mathrm{k}=7$ maka didapat cluster yang paling optimal yaitu $\mathrm{k}=2$ dengan nilai Davies Bouldin sebesar 0,558. Davies Bouldin Index dapat dikatakan baik jika nilai semakin kecil atau minimal maka hasil clustering yang didapat semakin baik (Kotu \& Deshpande, 2015).

Tabel 8. Hasil DBI pengujian $\mathrm{k}=2$ sampai k=7 pada aplikasi Rapidminer

\begin{tabular}{|c|c|}
\hline Cluster & Nilai Davies Bouldin \\
\hline$k=2$ & 0.558 \\
\hline$k=3$ & 0.601 \\
\hline$k=4$ & 0.622 \\
\hline$k=5$ & 0.692 \\
\hline$k=6$ & 0.742 \\
\hline$k=7$ & 0.745 \\
\hline
\end{tabular}

Pada penentuan cluster menggunakan metrik Davies Bouldin Index digunakan data centroid dari iterasi terakhir pada proses clustering.

\subsection{Pembahasan}

Berdasarkan proses clustering dengan algoritma K-means menggunakan aplikasi Rapidminer, maka menghasilkan informasi bahwa pada cluster 0 terdiri dari 46 items dengan Perguruan Tinggi Negeri yang paling diminati adalah UNPAD sebanyak 23 siswa, ITB sebanyak 20 siswa, UNDIP sebanyak 2 siswa dan UPI sebanyak 1 siswa. Pada cluster 1 terdiri dari 40 items dengan Perguruan Tinggi Negeri yang paling diminati adalah UNPAD sebanyak 24 siswa, UPI sebanyak 10 siswa, ITB sebanyak 3 siswa, UGM sebanyak 1 siswa, UNSRI sebanyak 1 siswa dan ISI sebanyak 1 siswa. Berdasarkan uraian tersebut, maka dapat disimpulkan bahwa cluster tertinggi berada pada cluster 0 yang terdiri dari 46 items dengan dominasi siswa lolos di Perguruan Tinggi Negeri UNPAD dan ITB dan cluster 1 menjadi cluster rendah yang terdiri dari 28 items dengan dominasi siswa lolos di Perguruan Tinggi Negeri UNPAD dan UPI.

\section{Kesimpulan}

Berdasarkan hasil penelitian mengenai pengelompokan data siswa yang lolos SNMPTN di SMAN 8 Bandung menggunakan algoritma K-Means maka diperoleh kesimpulan:

1. Data siswa lolos SNMPTN SMAN 8 Bandung dikelompokan dengan membuat design pemodelan yang dibentuk menjadi 2 cluster menggunakan aplikasi Rapidminer. Didapatkan hasil pada cluster 0 terdiri dari 46 items dan cluster 1 sebanyak 40 items. Maka dapat disimpulkan bahwa cluster tertinggi berada pada cluster 0 dan cluster 1 menjadi cluster rendah.

2. Berdasarkan validasi menggunakan metrik Davies Bouldin Index pada aplikasi Rapidminer maka diperoleh nilai ketepatan sebesar 0,558.

\section{Saran}

Guna mewujudkan penelitian selanjutnya yang lebih baik, penulis memberikan beberapa saran, yaitu :

1. Hasil penelitian ini dapat dijadikan evaluasi yang berkaitan dengan minat 
siswa sebelum mendaftar SNMPTN sehingga pihak sekolah dapat mengarahkan siswanya mengambil program studi/jurusan yang diminati

2. Gunakan metrik yang lain agar mendapatkan hasil pengelompokan yang lebih baik

3. Untuk penelitian selanjutnya gunakan metode lain seperti K-Medoid atau metode lain yang sesuai dengan tipe objek yang digunakan.

4. Buat aplikasi pencatatan siswa yang lolos SNMPTN sehingga sekolah memiliki data dari setiap tahunnnya.

\section{Referensi}

Amri, M. A., Windarto, A. P., Wanto, A., \& Damanik, I. S. (2019). Analisis Metode K-Means Pada Pengelompokan Perguruan Tinggi Menurut Provinsi Berdasarkan Fasilitas Yang Dimiliki Desa. KOMIK (Konferensi Nasional Teknologi Informasi Dan Komputer), 3(1), 674-679. https://doi.org/10.30865/komik.v3i1.16 77

Lestari, D., Anis, H., \& Khaeruddin, K. (2019). Analisis Hasil Belajar Mahasiswa Jurusan Fisika Berdasarkan Jalur Masuk (Snmptn, Sbmptn Dan Mandiri) Universitas Negeri Makassar. Jurnal Sains dan Pendidikan Fisika, 14(3).

Ndruru, E., \& Limbong, R. (2018). Implementasi Data Mining Dalam Pengelompokan Jurusan yang Diminati Siswa SMK Negeri 1 Lolowa'u menggunakan Metode Clustering. MEANS (Media Informasi Analisa Dan Sistem), 3(2), 107-113. http://ejournal.ust.ac.id/index.php/Jurn al_Means/article/view/273/pdfdssdx11

Prabowo, Y. S., \& Sunyoto, A. (2015). Sistem Pendukung Keputusan Pemilihan Jurusan SNMPTN Bagi Siswa SMAN 7 Purworejo. 182 CSRID Journal, Vol.6 No.3 Oktober 2014, Hal. 182-195, 9-10. ejournal.stikombali.ac.id/index.php/knsi/article/downlo $\mathrm{ad} / 438 / 91$

Putri, J., Purba, B., Zain, I., Wibowo, W., Ratnasari, V., \& Djunaedi, A. (2015). Pengelompokkan Rekam Jejak Sekolah Pada Seleksi Nasional Masuk Perguruan Tinggi Negeri (SNMPTN) di Institut Teknologi Sepuluh Nopember. I(1), 3-7.
Sadewo, M. G., Windarto, A. P., \& Hartama, D. (2017). Penerapan Datamining Pada Populasi Daging Ayam Ras Pedaging Di Indonesia Berdasarkan Provinsi Menggunakan K-Means Clustering. InfoTekJar (Jurnal Nasional Informatika Dan Teknologi Jaringan), 2(1), 60-67. https://doi.org/10.30743/infotekjar.v2i1. 164

Saifudin, A. (2018). Metode Data Mining Untuk Seleksi Calon Mahasiswa Pada Penerimaan Mahasiswa Baru Di Universitas Pamulang. 10(1), 25-36.

Kotu, V., \& Deshpande B. (2015) "Predictive Analytics and Data Mining Concepts and Practice with RapidMiner" Elsevier. 